\title{
The Effect of Once-Daily Gabapentin Extended Release Formulation in Patients With Postamputation Pain
}

\author{
Nebojsa Nick Knezevic 1,2,3, Tabish Aijaz' ${ }^{1}$ Kenneth D. Candido ${ }^{1,2,3}$, Svetlana Kovaleva ${ }^{1}$, \\ Alexei Lissounov ${ }^{1}$ and Ivana Knezevic ${ }^{1 *}$ \\ ${ }^{1}$ Department of Anesthesiology, Advocate Illinois Masonic Medical Center, Chicago, IL, United States, ${ }^{2}$ Department \\ of Anesthesiology, The University of Illinois at Chicago, Chicago, IL, United States, ${ }^{3}$ Department of Surgery, The University \\ of Illinois at Chicago, Chicago, IL, United States
}

Objectives: To compare gabapentin extended-release, a gastro-retentive formulation, in relieving postamputation pain among gabapentin-experienced and gabapentin-naïve patients.

Design: Open-labeled pilot study.

Subjects: Sixteen patients with postamputation pain (8 patients in the gabapentinexperienced and 8 patients in the gabapentin-naïve groups).

OPEN ACCESS

Edited by: Francisco R. Nieto, University of Granada, Spain

Reviewed by: Robert Warren Gould, Vanderbilt University, United States

Anna Maria Pittaluga

University of Genoa, Italy

*Correspondence:

Ivana Knezevic

drivanaknezevic@gmail.com

Specialty section: This article was submitted to

Neuropharmacology,

a section of the journa

Frontiers in Pharmacology

Received: 22 December 2018

Accepted: 23 April 2019

Published: 15 May 2019

Citation:

Knezevic NN, Aijaz T, Candido KD, Kovaleva S, Lissounov A and Knezevic I (2019) The Effect of Once-Daily Gabapentin Extended Release Formulation in Patients With

Postamputation Pain

Front. Pharmacol. 10:504. doi: 10.3389/fphar.2019.00504
Methods: Patients were started on gabapentin extended-release and were followed up for 8 weeks. Patients reported their pain severity during rest and movement using a numeric rating scale (NRS), interference of pain with daily activities using the modified brief pain inventory (MBPI) questionnaire, and treatment satisfaction using the treatment satisfaction questionnaire for medication (TSQM).

Results: Patients from both gabapentin-experienced and gabapentin-naïve groups achieved a significant and sustainable pain relief over the course of therapy. The pain scores at rest decreased in both gabapentin-experienced and gabapentin-naïve groups from $5.88 \pm 1.36$ and $4.88 \pm 2.95$ to $1.88 \pm 0.99$ and $1.38 \pm 1.51$, respectively. An average percent of pain relief with gabapentin extended-release was noted to be significant $(p<0.01)$ after 8 weeks of therapy among gabapentin-experienced $(81.25 \pm 16.42 \%)$ and gabapentin-naive groups $(85 \pm 17.73 \%)$ when compared to baseline for gabapentin-experienced (31.25 \pm 29\%) and gabapentin-naïve groups (36.25 $\pm 34.2 \%)$, respectively. Gabapentin-experienced and gabapentin-naïve groups had no significant difference in global satisfaction from treatment $(79.14 \pm 10.47$ and $83.3 \pm 20.82)$, convenience of treatment $(73.78 \pm 19.04$ and $90.44 \pm 11.66)$, effectiveness of treatment $(72.6 \pm 10.1$ and $79.73 \pm 11.6)$. The only statistically significant difference among gabapentin-experienced and gabapentin-naïve groups was found in adverse event tolerability (65.78 \pm 10.36 and $85.8 \pm 10.14, p<0.01)$.

Conclusion: Once-daily dosing of gabapentin-extended release showed significant improvement in pain severity and functional status, with no difference found between gabapentin-experienced versus gabapentin-naïve patients.

Keywords: gabapentin, extended release, postamputation pain, chronic pain, amputation 


\section{INTRODUCTION}

Postamputation pain (PAP) is defined as pain developing after a surgical amputation of a body part, which persists for several months after amputation and for which other causes of pain have been ruled out (Davis, 1993; Crombie et al., 1998). PAP is considered to be primarily a neuropathic type of pain, with its origins within both the central and peripheral nervous systems (Coderre et al., 1993; Nikolajsen et al., 2000; Melzack et al., 2001; Bittar et al., 2005; Flor, 2008; Foell et al., 2014). PAP has emerged as a primary predictor of patient's health and quality of life following surgery (Doth et al., 2010). The incidence of PAP has been reported to be 33-80\% (Richardson et al., 2006; Schley et al., 2008; Wilson et al., 2008; Dworkin et al., 2010b). This wide range is due to the wide variations in the studied populations and varied definitions of PAP (Richardson et al., 2006; Hunter et al., 2008; Schley et al., 2008; Wilson et al., 2008; Dworkin et al., 2010b; Kelle et al., 2017). There is a huge economic impact of PAP, as pain management is the biggest cost factor in the long-term care of these patients (Richardson et al., 2006; Schley et al., 2008; Wilson et al., 2008; Dworkin et al., 2010b). This additional cost is not only due to direct impact on patient's health and increased demand on healthcare resources, but is also indirectly due to burden on the patient's family and caregivers (Dworkin et al., 2010a; Duenas et al., 2016). However, the efficacies of current treatment modalities are questionable, given the low satisfaction rates reported widely in the literature (Finnerup et al., 2005; Oster et al., 2005; Rathmell and Kehlet, 2011).

Since PAP is considered to be a neuropathic pain, there is a special interest in using gabapentin for prevention and treatment of pain (Taylor et al., 1998). However, the adoption of gabapentin for the treatment of PAP is slow due to its high rate of adverse events, particularly at the initiation of therapy, which are responsible for a high rate of treatment abandonment in the early stages of implementation (Parsons et al., 2004). The side effect profile of gabapentin has been attributed to its short half-life, resulting in frequent dosing at short intervals and unpredictable absorption from the gut, causing inconsistent levels in the blood and making its titration difficult. A new formulation of gabapentin known as gastro-retentive or extended-release (ER) gabapentin has been developed to provide a slow rate of absorption from the gastrointestinal tract, which would result in increased tolerability of side effects without affecting its efficacy (Depomed, 2007). Gabapentin ER has been extensively studied for the treatment of postherpetic neuralgia. It has shown to be an effective analgesic, with lower rates of adverse events as compared to gabapentin immediate-release (IR) (Irving et al., 2009; Jensen et al., 2009; Sang et al., 2013). To date, no previous study has investigated the use of gabapentin ER for the treatment of PAP. For this purpose, we designed the present study to evaluate the efficacy and safety of gabapentin ER in relieving PAP. To evaluate the safety of gabapentin ER, we compared patients who were new to gabapentin therapy with patients who had taken gabapentin IR.

\section{MATERIALS AND METHODS}

This study was approved by the Advocate Health Care Institutional Review Board (IRB) and IND exemption was obtained from Food and Drug Administration (FDA). This was an open-labeled, single intervention study determining the efficacy and safety of gabapentin ER (Gralise ${ }^{\circledR}$, Kansas) use in patients experiencing PAP, which was defined as pain after amputation persisting for more than 6 months (Depomed, 2007). Written informed consent was obtained from all patients. Patients were included if they were older than 18 years and suffering from PAP, following limb amputation surgery due to peripheral vascular disease.

Patients were excluded if they met at least one of the following criteria: known allergic reaction to gabapentin, history of epilepsy/seizure disorder, dementia or any cognitive disorder interfering with assessment of pain or adverse reactions. Patients with severe cardiopulmonary disease, uncontrolled hypotension, uncontrolled hypertension, underlying liver disorder, untreated alcohol abuse, chronic diarrhea, dyspepsia, gastroduodenal ulcers, previous gastric reduction surgery, and chronic kidney disease requiring hemodialysis were also excluded from the study. To evaluate the safety of gabapentin, the patient population was divided into two cohort groups based on previous use or lack thereof of gabapentin, i.e., gabapentin-naïve and gabapentin-experienced. Gabapentin-naïve groups included patients with no previous history of gabapentin use, whereas the gabapentin-experienced group included patients who had taken gabapentin IR. Data gathered from the patients included patient characteristics such as age, sex, race/ethnicity, weight, height, body mass index, site of amputation and time duration since amputation in months. In accordance with Initiative on Methods, Measurement, and Pain Assessment in Clinical Trials (IMMPACT) recommendations, we used multiple endpoints in our trial, including an 11-point numeric rating scale (NRS) for pain intensity at rest and during movement which scores pain between 0 and 10 (Turk et al., 2008; Perrot and LanteriMinet, 2019). Interference in daily activities due to pain as well as relief provided by pain medications were assessed using the modified brief pain inventory (mBPI) questionnaire. The mBPI measures pain interference by calculating the mean of score from seven activities, i.e., general activity, walking, work, mood, enjoyment of life, relations with others, and sleep. The treatment satisfaction questionnaire for medication (TSQM) was used to assess the patient's perception of the treatment by measuring its effectiveness, tolerability of adverse events, convenience of therapy, and overall satisfaction from the treatment. mBPI and TSQM have been validated for the use in neuropathic pain syndromes and are routinely used in clinical trials to determine the efficacy of treatment (Zelman et al., 2005; Serpell et al., 2014; Perrot and Lanteri-Minet, 2019).

All the patients participating in the study were started on a once-daily dose of gabapentin ER using a titrating regimen, recommended by the United States Food and Drug Administration (FDA) for the treatment of postherpetic neuralgia (FDA, 2011). Patients who were already on gabapentin underwent a washout period of 2 weeks before starting the trial. 


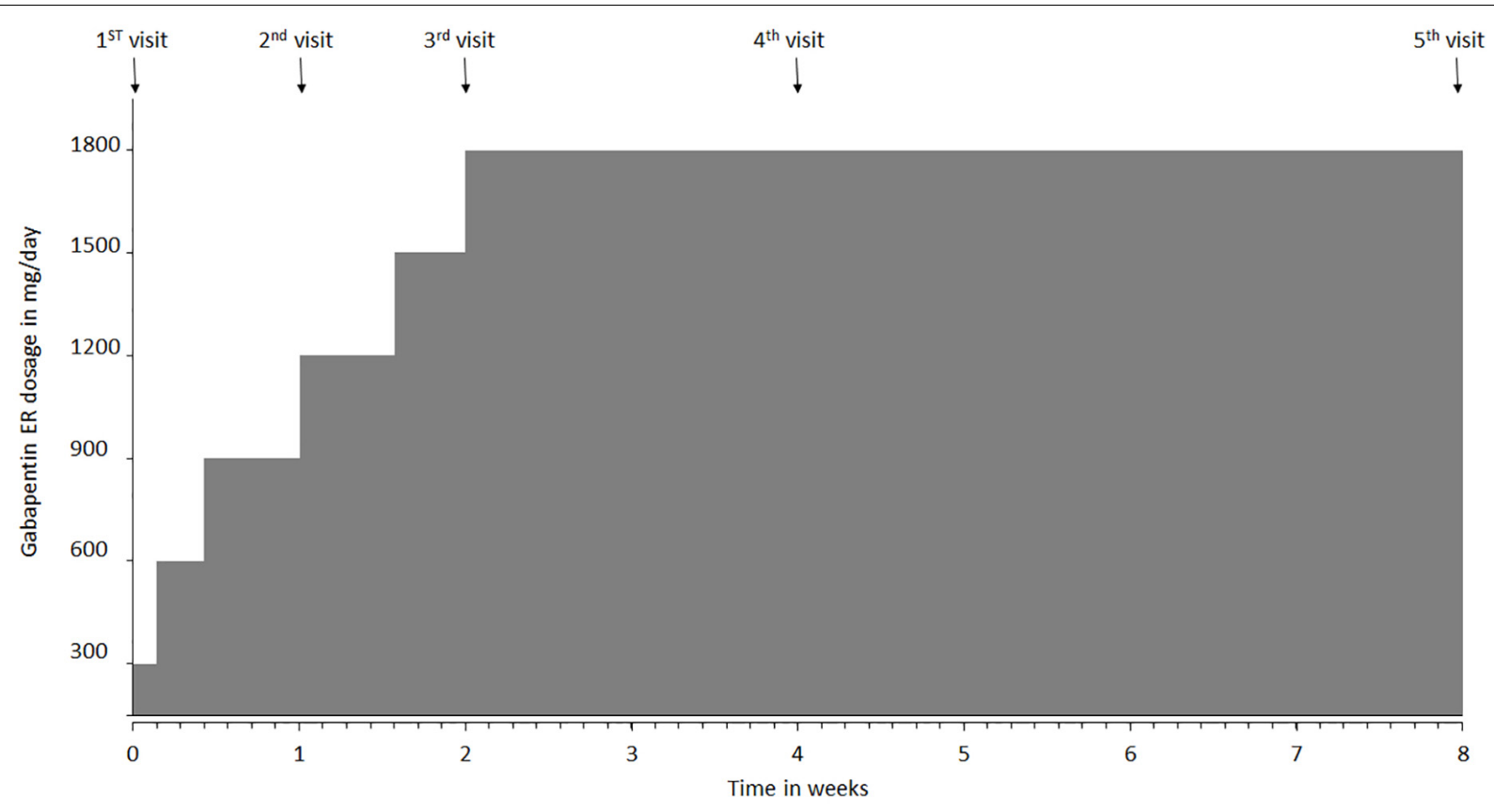

FIGURE 1 | Gabapentin extended-release (ER) titration schedule and clinic visit intervals over the course of the study. The first visit was conducted prior to starting gabapentin ER medication. Patients were instructed to take $300 \mathrm{mg}$ at night, then $600 \mathrm{mg}$ dose on day 2 , and $900 \mathrm{mg}$ on day 3 which was continued until day 6. Dosage was increased to $1200 \mathrm{mg}$ on day 7 (visit 2), followed by increase to $1500 \mathrm{mg}$ on day 11, and to $1800 \mathrm{mg}$ (max dose) on day 15, after their visit 3. Visit 4 occurred at week 4 , visit 5 at week 8 and visit 6 at week 10.

The dose was administered with an evening meal in order for the peak dose to occur in the early morning (Depomed, 2007). Patients were instructed to start gabapentin ER at $300 \mathrm{mg} /$ day dosing, gradually increasing the dose up to $1800 \mathrm{mg} /$ day over 2 weeks and continuing the dose of $1800 \mathrm{mg} /$ day for the next 6 weeks to complete the 8-week study period (Figure 1). Patients had a total of 6 visits, with the first visit after washout period and before starting medication. It was followed by visits at week 1, week 2, week 4, and week 8 . If patients did not desire to continue using gabapentin ER, the medication was withdrawn after a gradual downward titration over the next 8 days. Gabapentin ER was tapered down to $1200 \mathrm{mg}$ per day for 4 days, followed by $600 \mathrm{mg}$ per day for next 4 days and was stopped after that. We also had a follow-up visit at week 10 to evaluate patients after the completion of the study. This visit was meant to ensure safe withdrawal from gabapentin ER at the end of the study if so desired by the patients (Figure 1). Patients filled an mBPI questionnaire at the beginning and end of the study. During each visit, patients reported pain at rest and pain during movement using the NRS scale, along with any new adverse event that occurred since the previous visit. Patients were also administered the Columbia-Suicide Severity Rating Scale (C-SSRS) at each visit because increased suicidal ideation risk associated with gabapentin (Mula et al., 2013; FDA, 2017; Ghaly et al., 2018). Upon completion of the study, the treatment satisfaction questionnaire for medication was administered. Patients were allowed to continue using gabapentin ER after completion of the study if they were satisfied with the pain relief provided by the drug.

\section{Statistical Analysis}

Descriptive analysis was conducted for the baseline characteristics, i.e., proportion for categorical data and mean with standard deviation for continuous data. The statistical differences in baseline characteristics between the gabapentin-experienced and gabapentin-naïve groups were compared using Pearson's chi-squared test or Fischer's exact test for categorical data, and a $t$-test for independent samples for continuous data. The one-way repeated measure analysis of variance (ANOVA) test was used to compare the mean differences in pain at rest and pain during movement with time, with statistical significance set at the 5\% level. An independent samples $t$-test was run to determine if there were differences in pain interference and pain relief with medication between gabapentin-experienced and gabapentinnaïve groups. The differences in effectiveness, adverse events, convenience, and overall satisfaction between gabapentin-naïve and gabapentin-experienced groups were compared using a $t$-test for independent samples. Statistical significance was set at the $5 \%$ level for all the results. Data analysis was performed using SPSS 23.0 (IBM Corp. Released 2014. IBM SPSS Statistics for Windows, Version 23.0. Armonk, NY: IBM Corp.).

\section{RESULTS}

Eight patients suffering from PAP were recruited to each group of the study according to previous history of gabapentin use. This resulted in 6 males and 2 females being recruited in each group. No statistically significant difference was found in age, BMI, 
race/ethnicity, amputation site, or for time since amputation between gabapentin-naïve and gabapentin-experienced groups as shown in Table $\mathbf{1}$. In the gabapentin-experienced group, 3 patients were on gabapentin at the time of enrollment and only 1 patient was on concomitant opioid treatment, while no patient in gabapentin-naïve group was using opioid treatment. Use of non-opioid pain medications such as meloxicam, ibuprofen, acetaminophen, was more common in gabapentin-experienced group with 3 patients on such treatment, while only 1 patient was using non-opioid pain medications in gabapentin-naïve group.

There was a statistically significant difference in pain at rest during the different visits, $F(1,15)=27.6, p<0.001$, partial $\eta^{2}=0.648$ (Figure 2). Within group analysis, using repeated measures with Bonferroni adjustment, significant difference in pain at rest was shown on 3 rd visit compared to 1 st and 2 nd visits, which persisted until the 6th visit. Similarly, a statistically significant difference in pain during movement was seen during the different visits, $F(1,15)=49.7, p<0.001$, partial $\eta^{2}=0.768$ (Figure 3). Within group analysis, using repeated measures with Bonferroni adjustment, significant differences in pain during movement were identified on the 3 rd visit compared to 1 st and 2nd visit, which persisted until the 6th visit.

Pain interference reported by gabapentin-experienced patients was $(M=4.8, S D=2.2)$ and gabapentin-naïve patients at the end of study was $(M=5.1, S D=2.2)$, with no statistically significant difference between the groups, $M D=-0.55,95 \%$ CI $[-2.43,1.33], p=0.54$. Pain relief with medications reported by gabapentin-experienced patients at the end of study was $(M=35.71, S D=28.2)$ and gabapentin-naive patients was $(M=58.0, S D=21.7)$, with no statistically significant difference between the groups, $M D=8.5,95 \% \mathrm{CI}[-14.5,22.1]$, $p=0.67$ (Figure 4).

TABLE 1 | Baseline demographics and characteristics.

\begin{tabular}{|c|c|c|c|}
\hline Variable & $\begin{array}{l}\text { Gabapentin- } \\
\text { experienced }\end{array}$ & Gabapentin-naïve & $p$-value \\
\hline Sex & & & 1.00 \\
\hline Male & 6 & 6 & \\
\hline Female & 2 & 2 & \\
\hline Race & & & 0.411 \\
\hline Caucasian & 2 & 4 & \\
\hline Hispanic & 1 & 0 & \\
\hline African-American & 5 & 4 & \\
\hline Amputation site & & & 0.179 \\
\hline Toe unilateral & 2 & 2 & \\
\hline Toe bilateral & 1 & 0 & \\
\hline Below knee & 2 & 5 & \\
\hline Above knee & 3 & 0 & \\
\hline Upper extremity & 0 & 1 & \\
\hline Age (years) & $55.5 \pm 11.1$ & $55.4 \pm 9.8$ & 0.981 \\
\hline $\begin{array}{l}\text { Body mass index } \\
\mathrm{kg} / \mathrm{m} 2)\end{array}$ & $30.8 \pm 5.9$ & $29 \pm 2.4$ & 0.441 \\
\hline $\begin{array}{l}\text { Time since } \\
\text { amputation } \\
\text { (months) }\end{array}$ & $133.2 \pm 142.7$ & $100.6 \pm 79.8$ & 0.581 \\
\hline
\end{tabular}

The gabapentin-experienced group reported convenience of therapy at $90.4 \%$ and effectiveness at $79.7 \%$ compared to $73.8 \%$ for convenience of therapy and $72.6 \%$ for effectiveness reported by the gabapentin-naïve group. There were no significant differences in the proportions of convenience $(p=0.53)$ and effectiveness ( $p=0.21$ ) between the two groups. Gabapentinexperienced group reported acceptable tolerance of adverse effect at $85.8 \%$ as compared to $65.8 \%$ in the gabapentinnaïve group, which was a statistically significant difference, $p=0.002$. Gabapentin-naïve group scored $83.3 \%$ in the overall satisfaction associated with the therapy, compared to $79.1 \%$ score in the gabapentin-experienced group, however, there were no significant differences between the two groups, $p=0.62$ (Figure 5). Adverse events reported by the patients at each visit are mentioned in Table 2.

\section{DISCUSSION}

Our study found a significant reduction in PAP and interference of pain with daily functions after initiation of gabapentin ER therapy in both gabapentin-experienced and gabapentin-naïve patients. Our results are in line with other studies on the use of gabapentin ER in neuropathic pain showing a similar reduction in pain severity (Irving et al., 2009; Beal et al., 2012). Gabapentin ER has consistently shown improvement in postherpetic neuralgia pain in several clinical trials, leading to its approval by the FDA in 2011 (FDA, 2011). Since its approval, phase 3 clinical trial testing has proven it to be safe and effective at a dose of $1800 \mathrm{mg} /$ day for the treatment of postherpetic neuralgia (Irving et al., 2009; Jensen et al., 2009; Beal et al., 2012; Rauck et al., 2013; Sang et al., 2013; Kaye et al., 2014). To date, very few studies have evaluated the role of gabapentin ER in the treatment of other chronic neuropathic pain conditions (Sandercock et al., 2012; Kaye et al., 2014; North et al., 2016). There is limited data supporting the use of gabapentin ER to treat pain due to spinal stenosis, fibromyalgia and diabetic neuropathy (Sandercock et al., 2012; Kaye et al., 2014; North et al., 2016). So far, no research has been carried out to evaluate the use of gabapentin ER for the treatment of PAP.

To better understand the role of gabapentin in the treatment of PAP, it is important to understand its molecular structure and mechanism of action. Gabapentin, [1-(aminomethyl) cyclohexane acetic acid], is a synthetic analog of gammaaminobutyric acid (GABA), which subsequently inhibits pain neurotransmission, particularly targeting neuropathic pain pathways (Taylor et al., 1998). Several hypotheses have been proposed to explain the mechanism of action of gabapentin, one of which is modulation of sodium or calcium channels, but there is limited evidence to support this hypothesis (Brown et al., 1996; Moore et al., 2002; Chen and Mao, 2013). It is known that gabapentin has effects on the central nervous system via increased serotonin concentrations, which is partly responsible for its pharmacodynamic effect. Another explanation is the inhibition of the ventrolateral periaqueductal gray pathway in amygdala, which is considered crucial for its anticonvulsant effects and possibly contributive to its role in the alleviation of 


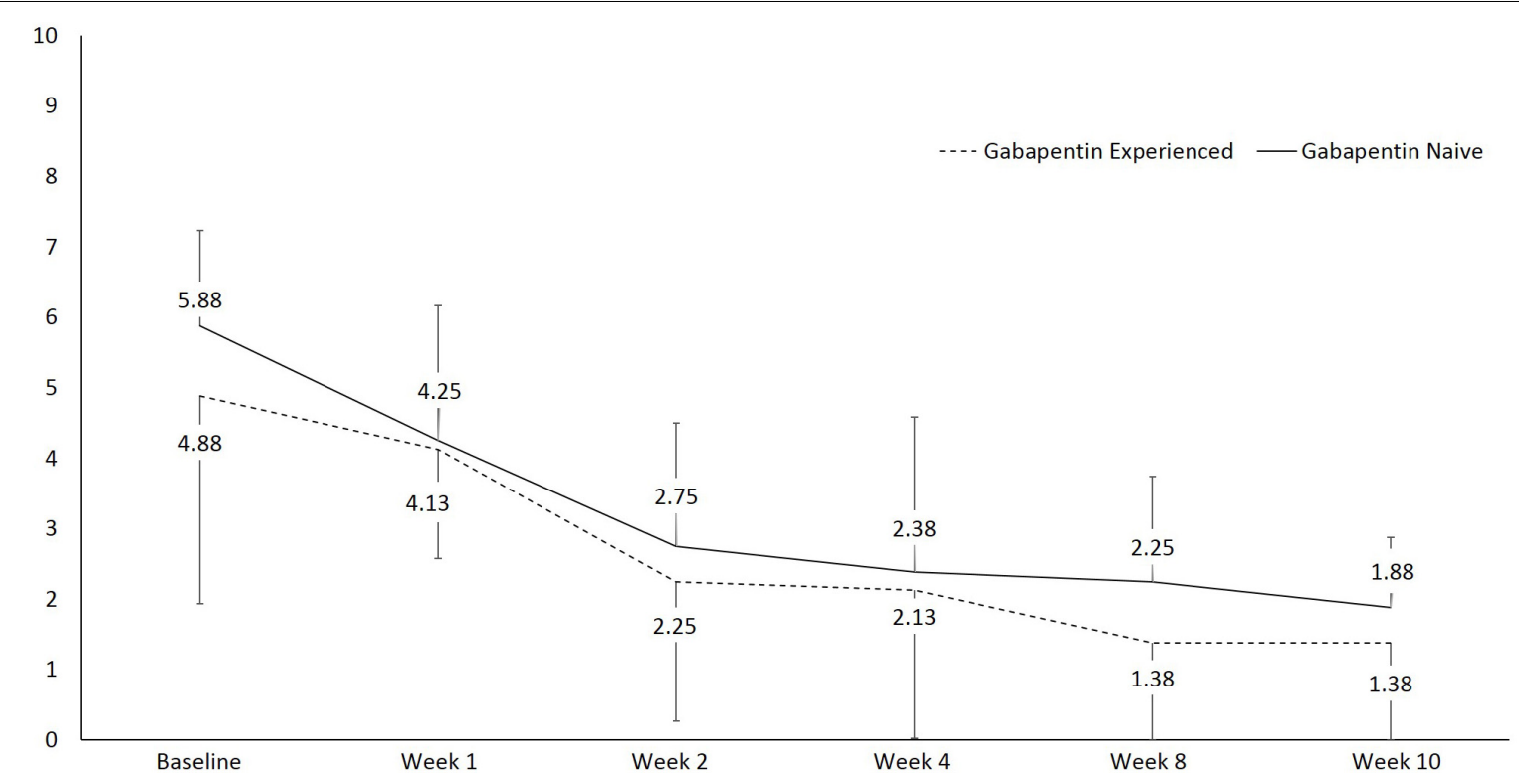

FIGURE 2 | Line graph showing pain at rest using numeric rating scale (NRS) over the course of the study.

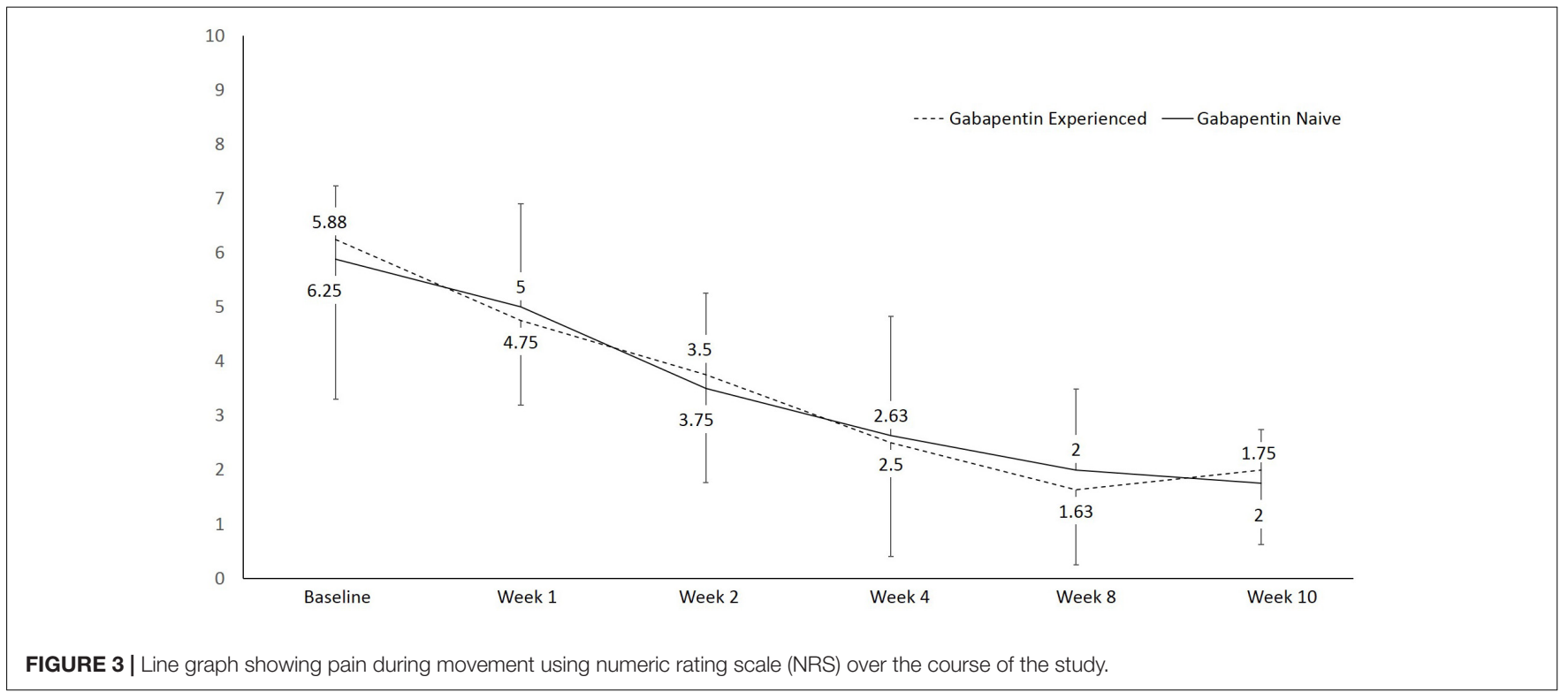

pain and anxiety (Tupal and Faingold, 2012). Some investigators have proposed a different mechanism, which involves the noradrenergic pathway by binding to the alpha-2 delta subunit in neural tissues to inhibit dorsal root ganglion transmission (Alden and Garcia, 2001).

Gabapentin ER has been evaluated as both once-daily and twice daily dosing in the past. In our study, we used a oncedaily dosage regimen only because previously published literature has not shown any differences in efficacy with either dosing regimen (Wang and Zhu, 2017). This has been confirmed by a meta-analysis conducted to compare different dosing regimens of gabapentin in the treatment of postherpetic neuralgia, which found that the once-daily dosing regimen of gabapentin ER is as effective as the twice daily dosing regimen. Another study by North et al. (2016) evaluated the safety and titration regimen of gabapentin ER in patients with fibromyalgia. Similar to our study, they also compared gabapentin-naïve vs. gabapentin-experienced patients and found encouraging results. Titration regimen, upper dose limit and safety profile was comparable to our study results (North et al., 2016). In a study of pharmacokinetics by Chen et al. (2011) gabapentin ER exhibited superior dose linearity compared with the gabapentin IR dosage form that allows for a reduction in dosing frequency, allowing a once-daily regimen.

Our results on gabapentin ER adverse effect tolerance were very encouraging. Most common adverse events in our study were dizziness, somnolence, and headache, which 

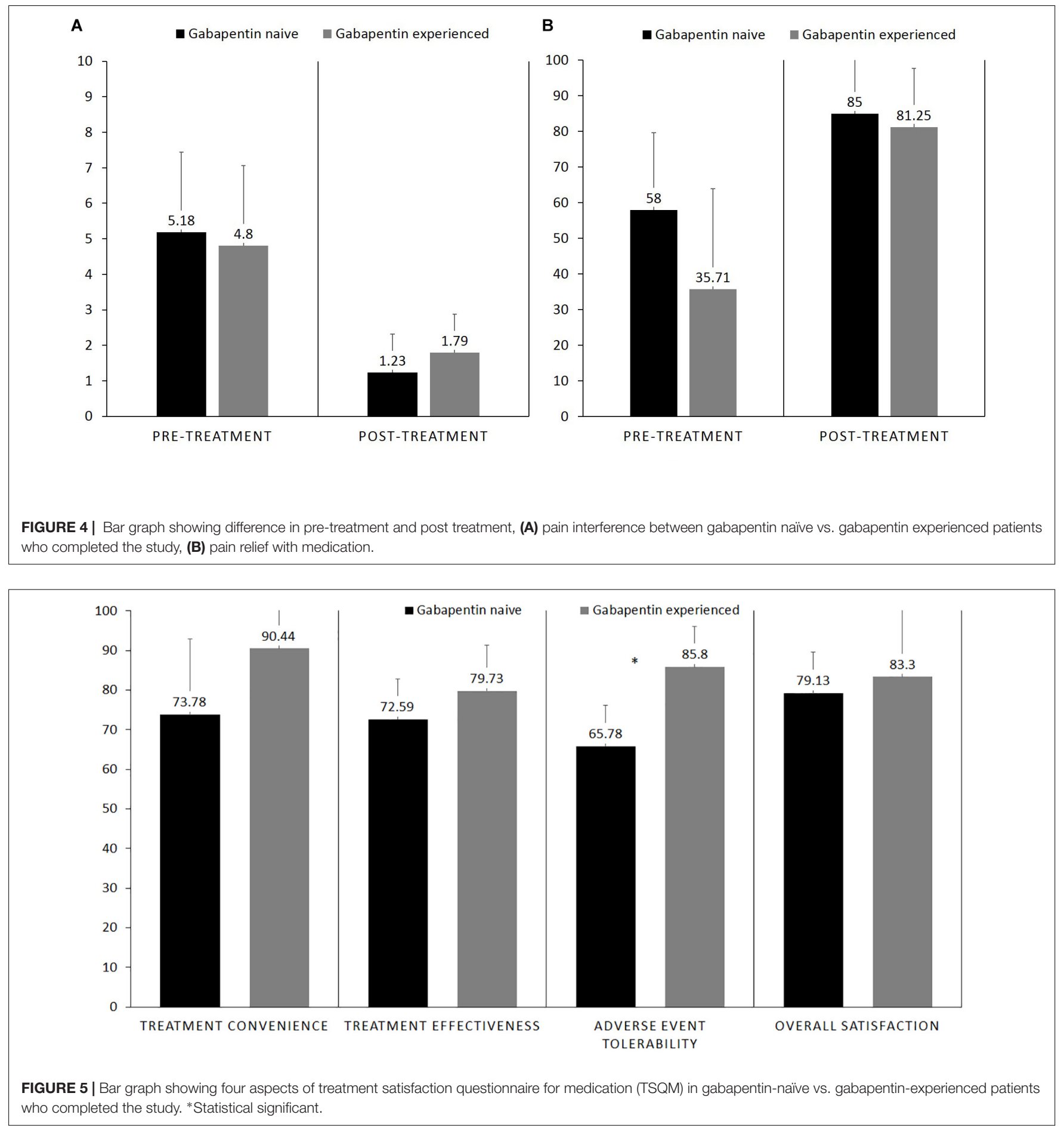

are consistent with the previously published literature (Beal et al., 2012). Rates of adverse events in our study were similar to previously published literature, which proves that gabapentin ER has good tolerability in patients suffering from PAP. Pharmacokinetic properties such as slower increase to a flatter peak may diminish the occurrence of adverse events compared with gabapentin IR. It also has a slower increase to the peak concentration and less drastic fluctuations in blood concentrations, which might possibly reduce the rate of adverse events compared to the IR formulation (Gordi et al., 2008; Kagan and Hoffman, 2009; Chen et al., 2011, 2013). The polymers in the gabapentin ER tablet are commonly used in the food industry and have not been reported to be associated with toxicological issues (Berner and Cowles, 2006). The intrasubject variability in gabapentin absorption is substantially less than that of 
TABLE 2 | Adverse events reported at each visit by the patients.

\begin{tabular}{lccccc}
\hline & Week 1 & Week 2 & Week 4 & Week 8 & Week 10 \\
\hline Dizziness & 3 & 3 & 4 & 1 & 0 \\
Headache & 1 & 0 & 0 & 1 & 0 \\
Diarrhea & 1 & 2 & 1 & 3 & 1 \\
Somnolence & 1 & 2 & 2 & 2 & 1 \\
Vivid dreaming & 0 & 1 & 0 & 0 & 0 \\
Occasionalreflux & 0 & 1 & 0 & 0 & 0 \\
Nausea & 0 & 1 & 1 & 2 & 0 \\
Dry mouth & 0 & 0 & 0 & 1 & 0 \\
Blurry vision & 0 & 0 & 0 & 1 & 0 \\
\hline
\end{tabular}

the intersubject variability; thus gabapentin plasma level is dependent on dose (Gidal et al., 2000).

We showed that gabapentin is safe to use as up to a dose of $1800 \mathrm{mg} /$ day in patients with PAP. We also demonstrated that it is safe to titrate gabapentin to its maintenance dose over a 2-week period in both gabapentin-naïve and gabapentinexperienced patients. For this reason, the FDA recommended dose titrations up to $1800 \mathrm{mg} / \mathrm{day}$, over 2 weeks, at the time of approval of gabapentin ER for postherpetic neuralgia (FDA, 2011). Once-daily dosing of $1800 \mathrm{mg} /$ day is a standard dose of gabapentin ER used for postherpetic neuralgia (Fan et al., 2014). Safety profile of gabapentin ER was studied in patients suffering from postherpetic neuralgia, where it was found to be safe with good adverse effect tolerability at doses of up to $1800 \mathrm{mg} /$ day which were used in our study (Irving et al., 2009; Jensen et al., 2009). Gabapentin ER has an extended duration and results in less fluctuations in blood concentrations, making it possible to use lower daily doses as compared to gabapentin IR (Kagan and Hoffman, 2009). It is important to remember that gabapentin IR has been used at doses of up to $3600 \mathrm{mg} /$ day with no significant changes in the adverse event profile (Backonja and Glanzman, 2003). To date, no study has been published comparing gabapentin ER and IR formulation at doses higher than $3000 \mathrm{mg} /$ day. Cowles et al. (2012) have used gabapentin ER in postmenopausal women with hot flashes with a daily dose of $3000 \mathrm{mg}$ with no significant differences in the adverse effect profile. This study was initiated in February 2005 following positive results from a phase 1 trial in which gabapentin ER demonstrated a pharmacokinetic profile suitable for twice-daily dosing. In two pharmacokinetic studies, gabapentin ER achieved improved bioavailability at higher doses (Depomed, 2007).

Our study also demonstrated that gabapentin ER is effective in relieving PAP. Our study was designed to compare the role of gabapentin ER between gabapentin-naïve and gabapentinexperienced patients; however, we neither had a placebo nor other medication group, which could have served as true control group(s). There is limited literature available comparing gabapentin with placebo in PAP. A noteworthy trial was conducted by Smith et al. comparing gabapentin with placebo in patients with PAP, which did fail to show significant pain relief in patients on gabapentin (Smith et al., 2005). However, the baseline pain scores were significantly lower as compared to our populations, which might explain this difference. Bone et al. (2002) showed a significant improvement in pain scores with the use of gabapentin in patients with postamputation phantom pain only. In this study, baseline pain intensity and percentage of pain relief with gabapentin were similar to our trial. We believe that the results from these two studies support our inference that gabapentin ER is similar in efficacy as compared to gabapentin IR. Recently, another formulation of gabapentin, gabapentin enacarbil, has been approved as once-daily dose for the treatment of postherpetic neuralgia (Backonja et al., 2011; Harden et al., 2013). Similar to Gabapentin ER, Gabapentin enacarbil has been shown to be safe and effective up to doses of 2400-3600 mg/day in patients suffering from postherpetic neuralgia (Calkins et al., 2016). We believe that both gabapentin ER and gabapentin enacarbil have the potential to replace gabapentin IR; however, a direct comparison between the two formerly described extended duration formulations is needed before reaching any conclusions.

Our study limited the maximum dose of gabapentin ER to $1800 \mathrm{mg} /$ day, which is equivalent to the commonly used dosage of gabapentin IR for the treatment of PAP. However, it is important to determine the maximum dose, which can be used to treat PAP without increasing risks of serious adverse effects. Secondly, we excluded patients with end-stage renal disease because of the known renal metabolism and excretion of gabapentin, which would require a dosage adjustment and because of a potential factor for bias in interpreting the attained results. Although gabapentin ER has been shown to be safe in patients with end-stage renal disease in a previous randomized control trial, further confirmation of the safety of gabapentin ER in this subgroup is needed. Lastly, it is also important to consider doing a long-term followup study to assess whether the effects of this medication in this patient population is sustainable over long period of time. Furthermore, costs of gabapentin ER therapy should be considered before deciding its role in the treatment of PAP. We therefore suggest that a detailed analysis of total costs associated with gabapentin therapy be evaluated, which is possibly only done in a large clinical trial aimed at assessing patients over a longer period of time than what has been accomplished to date.

\section{CONCLUSION}

We found that a gabapentin ER formulation both alleviates the pain severity and improves the functional status of patients suffering from PAP. Moreover, we did not find any new or unusual adverse events from the use of gabapentin ER. We are extremely optimistic that gabapentin ER may be of great value clinically for patients suffering from PAP.

\section{ETHICS STATEMENT}

Study was approved by Advocate Healthcare Institutional Review Board. 


\section{AUTHOR CONTRIBUTIONS}

$\mathrm{NK}$ and $\mathrm{KC}$ designed the study, revised the manuscript, and made the final corrections. NK, $\mathrm{AL}$, and IK

\section{REFERENCES}

Alden, K. J., and Garcia, J. (2001). Differential effect of gabapentin on neuronal and muscle calcium currents. J. Pharmacol. Exp. Ther. 297, 727-735.

Backonja, M., and Glanzman, R. L. (2003). Gabapentin dosing for neuropathic pain: evidence from randomized, placebo-controlled clinical trials. Clin. Ther. 25, 81-104. doi: 10.1016/s0149-2918(03)90011-7

Backonja, M. M., Canafax, D. M., and Cundy, K. C. (2011). Efficacy of gabapentin enacarbil vs placebo in patients with postherpetic neuralgia and a pharmacokinetic comparison with oral gabapentin. Pain Med. 12, 1098-1108. doi: 10.1111/j.1526-4637.2011.01139.x

Beal, B., Moeller-Bertram, T., Schilling, J. M., and Wallace, M. S. (2012). Gabapentin for once-daily treatment of post-herpetic neuralgia: a review. Clin. Interv. Aging 7, 249-255. doi: 10.2147/CIA.S23783

Berner, B., and Cowles, V. E. (2006). Case studies in swelling polymeric gastric retentive tablets. Expert Opin. Drug Deliv. 3, 541-548. doi: 10.1517/17425247. 3.4 .541

Bittar, R. G., Otero, S., Carter, H., and Aziz, T. Z. (2005). Deep brain stimulation for phantom limb pain. J. Clin. Neurosci. 12, 399-404. doi: 10.1016/j.jocn.2004. 07.013

Bone, M., Critchley, P., and Buggy, D. J. (2002). Gabapentin in postamputation phantom limb pain: a randomized, double-blind, placebo-controlled, crossover study. Reg. Anesth. Pain Med. 27, 481-486. doi: 10.1097/00115550200209000-00007

Brown, J., Bowden, P., Singh, L., and Gee, N. (1996). Mechanisms of action of gabapentin. Rev. Contemp. Pharmacother. 7, 203-214.

Calkins, A. M., Gudin, J., Gidal, B., Jaros, M. J., Kim, R., and Shang, G. (2016). Impact of data imputation methodology on pain assessment over 24 hours in a randomized, placebo-controlled study of gabapentin enacarbil in patients with neuropathic pain associated with postherpetic neuralgia. Pain Med. 17, 728-736. doi: 10.1093/pm/pnv072

Chen, C., Cowles, V. E., and Hou, E. (2011). Pharmacokinetics of gabapentin in a novel gastric-retentive extended-release formulation: comparison with an immediate-release formulation and effect of dose escalation and food. J. Clin. Pharmacol. 51, 346-358. doi: 10.1177/0091270010368411

Chen, C., Han, C. H., Sweeney, M., and Cowles, V. E. (2013). Pharmacokinetics, efficacy, and tolerability of a once-daily gastroretentive dosage form of gabapentin for the treatment of postherpetic neuralgia. J. Pharm. Sci. 102, 1155-1164. doi: 10.1002/jps.23467

Chen, L., and Mao, J. (2013). Update on neuropathic pain treatment: ion channel blockers and gabapentinoids. Curr. Pain Headache Rep. 17:359. doi: 10.1007/ s11916-013-0359-2

Coderre, T. J., Katz, J., Vaccarino, A. L., and Melzack, R. (1993). Contribution of central neuroplasticity to pathological pain: review of clinical and experimental evidence. Pain 52, 259-285. doi: 10.1016/0304-3959(93) 90161-h

Cowles, V. E., Gordi, T., and Hou, S. Y. (2012). Steady-state pharmacokinetics of gabapentin after administration of a novel gastroretentive extended-release formulation in postmenopausal women with vasomotor symptoms. Clin. Drug Investig. 32, 593-601. doi: 10.2165/11634520-000000000-00000

Crombie, I. K., Davies, H. T., and Macrae, W. A. (1998). Cut and thrust: antecedent surgery and trauma among patients attending a chronic pain clinic. Pain 76, 167-171. doi: 10.1016/s0304-3959(98)00038-4

Davis, R. W. (1993). Phantom sensation, phantom pain, and stump pain. Arch. Phys. Med. Rehabil. 74, 79-91.

Depomed (2007). Gabapentin extended-release - depomed: gabapentin er, gabapentin gastric retention, gabapentin GR. Drugs $R \quad D \quad 8,317-320$. doi: 10.2165/00126839-200708050-00005

Doth, A. H., Hansson, P. T., Jensen, M. P., and Taylor, R. S. (2010). The burden of neuropathic pain: a systematic review and meta-analysis of health utilities. Pain 149, 338-344. doi: 10.1016/j.pain.2010.02.034 collected the data. AL, TA, and IK analyzed the data and interpreted the results. SK and TA wrote the manuscript. All authors approved the final version of the manuscript.

Duenas, M., Ojeda, B., Salazar, A., Fernandez-Palacin, F., Mico, J. A., Torres, L. M., et al. (2016). Use and satisfaction with the healthcare system of the chronic pain patients in Spain: results from a nationwide study. Curr. Med. Res. Opin. 32, 1813-1820. doi: 10.1080/03007995.2016.1211519

Dworkin, R. H., Malone, D. C., Panarites, C. J., Armstrong, E. P., and Pham, S. V. (2010a). Impact of postherpetic neuralgia and painful diabetic peripheral neuropathy on health care costs. J. Pain 11, 360-368. doi: 10.1016/j.jpain.2009. 08.005

Dworkin, R. H., McDermott, M. P., and Raja, S. N. (2010b). Preventing chronic postsurgical pain: how much of a difference makes a difference?. Anesthesiology 112, 516-518. doi: 10.1097/aln.0b013e3181cf4253

Fan, H., Yu, W., Zhang, Q., Cao, H., Li, J., Wang, J., et al. (2014). Efficacy and safety of gabapentin $1800 \mathrm{mg}$ treatment for post-herpetic neuralgia: a metaanalysis of randomized controlled trials. J. Clin. Pharm. Ther. 39, 334-342. doi: $10.1111 /$ jcpt. 12167

FDA (2011). Gralise Prescribing Information. Available at: https://www.accessdata. fda.gov/drugsatfda_docs/label/2011/022544s000lbl.pdf (accessed December 21, 2018).

FDA (2017). Neurontin (Gabapentin) Prescribing Information. Available at: https://www.accessdata.fda.gov/drugsatfda_docs/label/2017/020235s064_ 020882s047 021129s046lbl.pdf (accessed December 21, 2018).

Finnerup, N. B., Otto, M., McQuay, H. J., Jensen, T. S., and Sindrup, S. H. (2005). Algorithm for neuropathic pain treatment: an evidence based proposal. Pain 118, 289-305. doi: 10.1016/j.pain.2005.08.013

Flor, H. (2008). Maladaptive plasticity, memory for pain and phantom limb pain: review and suggestions for new therapies. Expert Rev. Neurother. 8, 809-818. doi: 10.1586/14737175.8.5.809

Foell, J., Andoh, J., Bekrater-Bodmann, R., Diers, M., Fuchs, X., Colloca, L., et al. (2014). Peripheral origin of phantom limb pain: is it all resolved? Pain 155, 2205-2206. doi: 10.1016/j.pain.2014.08.028

Ghaly, R. F., Plesca, A., Rana, S., Candido, K. D., and Knezevic, N. N. (2018). Gabapentin-related suicide: myth or fact? Surg. Neurol. Int. 9:210. doi: 10.4103/ sni.sni_420_17

Gidal, B. E., Radulovic, L. L., Kruger, S., Rutecki, P., Pitterle, M., and Bockbrader, H. N. (2000). Inter- and intra-subject variability in gabapentin absorption and absolute bioavailability. Epilepsy Res. 40, 123-127. doi: 10.1016/s0920-1211(00) 00117-0

Gordi, T., Hou, E., Kasichayanula, S., and Berner, B. (2008). Pharmacokinetics of gabapentin after a single day and at steady state following the administration of gastric-retentive- extended-release and immediaterelease tablets: a randomized, open-label, multiple-dose, three-way crossover, exploratory study in healthy subjects. Clin. Ther. 30, 909-916 doi: 10.1016/j.clinthera.2008.05.008

Harden, R. N., Freeman, R., Rainka, M., Zhang, L., Bell, C., Berges, A., et al. (2013). A phase 2a, randomized, crossover trial of gabapentin enacarbil for the treatment of postherpetic neuralgia in gabapentin inadequate responders. Pain Med. 14, 1918-1932. doi: 10.1111/pme.12227

Hunter, J. P., Katz, J., and Davis, K. D. (2008). Stability of phantom limb phenomena after upper limb amputation: a longitudinal study. Neuroscience 156, 939-949. doi: 10.1016/j.neuroscience.2008.07.053

Irving, G., Jensen, M., Cramer, M., Wu, J., Chiang, Y. K., Tark, M., et al. (2009). Efficacy and tolerability of gastric-retentive gabapentin for the treatment of postherpetic neuralgia: results of a double-blind, randomized, placebo-controlled clinical trial. Clin. J. Pain 25, 185-192. doi: 10.1097/AJP. 0b013e3181934276

Jensen, M. P., Chiang, Y. K., and Wu, J. (2009). Assessment of pain quality in a clinical trial of gabapentin extended release for postherpetic neuralgia. Clin. J. Pain 25, 286-292. doi: 10.1097/AJP.0b013e318192bf87

Kagan, L., and Hoffman, A. (2009). Biopharmaceutical aspects of gastro-retentive dosage forms: the gabapentin paradigm. J. Drug Deliv. Sci. Technol. 19, 233-239. doi: 10.1016/s1773-2247(09)50046-9 
Kaye, A. D., Beuno, F. R., Katalenich, B., Stell, C., Liu, H., Rosinia, F. A., et al. (2014). The effects of gastroretentive gabapentin (Gralise(R)) on spinal stenosis patients with radicular pain. Pain Physician 17, 169-178.

Kelle, B., Kozanoğlu, E., Biçer, Ö, and Tan, İ. (2017). Association between phantom limb complex and the level of amputation in lower limb amputee. Acta Orthop. Traumatol. Turc. 51, 142-145. doi: 10.1016/j.aott.2017.02.007

Melzack, R., Coderre, T. J., Katz, J., and Vaccarino, A. L. (2001). Central neuroplasticity and pathological pain. Ann. N. Y. Acad. Sci. 933, 157-174. doi: 10.1111/j.1749-6632.2001.tb05822.x

Moore, K. A., Baba, H., and Woolf, C. J. (2002). Gabapentin- actions on adult superficial dorsal horn neurons. Neuropharmacology 43, 1077-1081. doi: 10.1016/s0028-3908(02)00226-5

Mula, M., Kanner, A. M., Schmitz, B., and Schachter, S. (2013). Antiepileptic drugs and suicidality: an expert consensus statement from the task force on therapeutic strategies of the ILAE commission on neuropsychobiology. Epilepsia 54, 199-203. doi: 10.1111/j.1528-1167.2012.03688.x

Nikolajsen, L., Ilkjaer, S., and Jensen, T. S. (2000). Relationship between mechanical sensitivity and postamputation pain: a prospective study. Eur. J. Pain 4, $327-$ 334. doi: 10.1053/eujp.2000.0194

North, J. M., Hong, K. S., and Rauck, R. L. (2016). The effect of a novel form of extended-release gabapentin on pain and sleep in fibromyalgia subjects: an open-label pilot study. Pain Pract. 16, 720-729. doi: 10.1111/papr.12319

Oster, G., Harding, G., Dukes, E., Edelsberg, J., and Cleary, P. D. (2005). Pain, medication use, and health-related quality of life in older persons with postherpetic neuralgia: results from a population-based survey. J. Pain 6, 356-363. doi: 10.1016/j.jpain.2005.01.359

Parsons, B., Tive, L., and Huang, S. (2004). Gabapentin: a pooled analysis of adverse events from three clinical trials in patients with postherpetic neuralgia. Am. J. Geriatr. Pharmacother. 2, 157-162. doi: 10.1016/j.amjopharm.2004.09.004

Perrot, S., and Lanteri-Minet, M. (2019). Patients' global impression of change (PGIC) in the management of peripheral neuropathic pain: clinical relevance and correlations in daily practice. Eur. J. Pain doi: 10.1002/ejp.1378 [Epub ahead of print].

Rathmell, J. P., and Kehlet, H. (2011). Do we have the tools to prevent phantom limb pain? Anesthesiology 114, 1021-1024. doi: 10.1097/aln.0b013e31820fc80d

Rauck, R. L., Irving, G. A., Wallace, M. S., Vanhove, G. F., and Sweeney, M. (2013). Once-daily gastroretentive gabapentin for postherpetic neuralgia: integrated efficacy, time to onset of pain relief and safety analyses of data from two phase 3, multicenter, randomized, double-blind, placebo-controlled studies. J. Pain Symptom Manage. 46, 219-228. doi: 10.1016/j.jpainsymman.2012.07.011

Richardson, C., Glenn, S., Nurmikko, T., and Horgan, M. (2006). Incidence of phantom phenomena including phantom limb pain 6 months after major lower limb amputation in patients with peripheral vascular disease. Clin. J. Pain 22, 353-358. doi: 10.1097/01.ajp.0000177793.01415.bd

Sandercock, D., Cramer, M., Biton, V., and Cowles, V. E. (2012). A gastroretentive gabapentin formulation for the treatment of painful diabetic peripheral neuropathy: efficacy and tolerability in a double-blind, randomized, controlled clinical trial. Diabetes Res. Clin. Pract. 97, 438-445. doi: 10.1016/j.diabres.2012. 03.010

Sang, C. N., Sathyanarayana, R., Sweeney, M., and Dm- (1796)Study Investigatorscpesnm (2013). Gastroretentive gabapentin (G-GR) formulation reduces intensity of pain associated with postherpetic neuralgia (PHN). Clin. J Pain 29, 281-288. doi: 10.1097/AJP.0b013e318258993e

Schley, M. T., Wilms, P., Toepfner, S., Schaller, H. P., Schmelz, M., Konrad, C. J., et al. (2008). Painful and nonpainful phantom and stump sensations in acute traumatic amputees. J. Trauma 65, 858-864. doi: 10.1097/TA. 0b013e31812eed9e

Serpell, M., Gater, A., Carroll, S., Abetz-Webb, L., Mannan, A., and Johnson, R. (2014). Burden of post-herpetic neuralgia in a sample of UK residents aged 50 years or older: findings from the Zoster Quality of Life (ZQOL) study. Health Qual. Life Outcomes 12:92. doi: 10.1186/1477-7525-12-92

Smith, D. G., Ehde, D. M., Hanley, M. A., Campbell, K. M., Jensen, M. P., Hoffman, A. J., et al. (2005). Efficacy of gabapentin in treating chronic phantom limb and residual limb pain. J. Rehabil. Res. Dev. 42, 645. doi: 10.1682/jrrd.2005.05.0082

Taylor, C. P., Gee, N. S., Su, T. Z., Kocsis, J. D., Welty, D. F., Brown, J. P., et al. (1998). A summary of mechanistic hypotheses of gabapentin pharmacology. Epilepsy Res. 29, 233-249. doi: 10.1016/s0920-1211(97)00084-3

Tupal, S., and Faingold, C. L. (2012). The amygdala to periaqueductal gray pathway: plastic changes induced by audiogenic kindling and reversal by gabapentin. Brain Res. 1475, 71-79. doi: 10.1016/j.brainres.2012.07.044

Turk, D. C., Dworkin, R. H., McDermott, M. P., Bellamy, N., Burke, L. B., Chandler, J. M., et al. (2008). Analyzing multiple endpoints in clinical trials of pain treatments: IMMPACT recommendations. Initiative on methods, measurement, and pain assessment in clinical trials. Pain 139, 485-493. doi: 10.1016/j.pain.2008.06.025

Wang, J., and Zhu, Y. (2017). Different doses of gabapentin formulations for postherpetic neuralgia: a systematical review and meta-analysis of randomized controlled trials. J. Dermatolog. Treat. 28, 65-77. doi: 10.3109/09546634.2016. 1163315

Wilson, J. A., Nimmo, A. F., Fleetwood-Walker, S. M., and Colvin, L. A. (2008). A randomised double blind trial of the effect of pre-emptive epidural ketamine on persistent pain after lower limb amputation. Pain 135, 108-118. doi: 10.1016/j. pain.2007.05.011

Zelman, D. C., Gore, M., Dukes, E., Tai, K. S., and Brandenburg, N. (2005). Validation of a modified version of the brief pain inventory for painful diabetic peripheral neuropathy. J. Vasc. Nurs. 23, 97-104. doi: 10.1016/j.jvn.2005. 06.004

Conflict of Interest Statement: Depomed, Inc. provided Gralise medication for the study purpose without any charge to the subjects/subjects' insurance.

The authors declare that the research was conducted in the absence of any commercial or financial relationships that could be construed as a potential conflict of interest.

Copyright (C) 2019 Knezevic, Aijaz, Candido, Kovaleva, Lissounov and Knezevic. This is an open-access article distributed under the terms of the Creative Commons Attribution License (CC BY). The use, distribution or reproduction in other forums is permitted, provided the original author(s) and the copyright owner(s) are credited and that the original publication in this journal is cited, in accordance with accepted academic practice. No use, distribution or reproduction is permitted which does not comply with these terms. 